Journal of Social Sciences 6 (2): 265-271, 2010

ISSN 1549-3652

(C) 2010 Science Publications

\title{
Work-Family Conflict among Junior Physicians: Its Mediating Role in the Relationship between Role Overload and Emotional Exhaustion
}

\author{
Aminah Ahmad \\ Department of Professional Development and Continuing Education, \\ Faculty of Educational Studies, University Putra Malaysia, \\ 43400 Serdang, Selangor, Malaysia
}

\begin{abstract}
Problem statement: The use of a mediation model for understanding the mediating impact of work-family conflict on the relationship between role overload and emotional exhaustion has not been given much attention. Approach: This study tested a mediation model consisting of emotional exhaustion as the dependent variable and role overload as the independent variable, with work-family conflict as its mediator. Data were gathered from a sample of 220 female junior physicians aged 40 years and below, having at least one child as well as working full-time in 14 public hospitals in Malaysia, using self-administered questionnaires. The data were analyzed using correlation and multiple regression analyses. Results: Results of correlation analyses revealed that role overload was significantly related to work-family conflict and emotional exhaustion and work-family conflict was significantly related to emotional exhaustion. Results of a series of multiple regression analyzed indicated that work-family conflict partially mediated the relationship between role overload and emotional exhaustion. Conclusion/Recommendations: Junior physicians who experience role overload seem to be more emotionally drained and seem to experience greater conflict between work and family roles. There is a need to reduce the role overload that physicians experience by reviewing the ratio between physicians and patients and re-assessing the number of work hours and the weekly frequency of on-calls. Limiting on-call frequency and hours may be more likely to reduce work-family conflict as well as emotional exhaustion.
\end{abstract}

Key words: Work-family conflict, role overload, emotional exhaustion, junior physicians

\section{INTRODUCTION}

With the increase in the number of female physicians entering the work force and the need to balance the demands of their work and family lives, female physicians are more likely to experience workfamily conflict involving incompatible demands. A study on gender differences in workload among professionals has shown that men spent more time in professional work and women more time in childcare and women perceived themselves as responsible for childcare activities at home (Bergman et al., 2008). This illustrates that apart from paid work, female physicians are mainly responsible for unpaid work at home and thus carried a double workload. With the double workload, the female physicians are more likely to experience conflict between work and family roles. Greenhaus and Beutell (1985) and Kahn et al. (1964) conceptualized work-family conflict as a form of interrole conflict in which the role pressures from the work and family domains are mutually incompatible, such that participation in one role makes it more difficult to participate in the other. The experience of work-family conflict among professionals including physicians have been reported by researchers (Ray and Miller, 1994; Baron and Kenny, 1986a; Bergman et al., 2008). Acknowledging the experience of work-family conflict among physicians, several researchers have studied reduced workload as a condition that could reduce the conflict (Greenhaus and Beutell, 1985; Lingard and Francis, 2006) while other researchers have studied the consequences of the conflict including emotional exhaustion (Innstrand et al., 2008; Baron and Kenny, 1986a; Bergman et al., 2008; Fu and Shaffer, 2001).

Emotional exhaustion refers to feelings of being emotionally overextended and depleted of one's emotional resources (Shaufelli et al., 2009). There are evidences from previous studies that physicians experience emotional exhaustion (Greenglass et al., 2003; Peiro et al., 2001; Maslach, 1993). The emotional exhaustion experienced has been associated with various organizational outcomes such as turnover, lack 
of organizational commitment and withdrawal behavior (Alacacioglu et al., 2009). The recognition of negative psychological consequences of emotional exhaustion has directed attention towards the role of contributing factors such as appropriate workload and reduced workfamily conflict in addressing the problem of emotional exhaustion experienced by employees. Although previous studies have reported the effects of role overload (Chopra et al., 2004; Innstrand et al., 2008; Piesah et al., 2009; Maslach et al., 2001) and workfamily conflict (Innstrand et al., 2008; Baron and Kenny, 1986a; Bergman et al., 2008; Fu and Shaffer, 2001) and their interactions with other variables on emotional exhaustion, the use of a model for understanding the mediating impact of work-family conflict on the relationship between the role overload as a stressor and emotional exhaustion as a consequence has not been given much attention.

This study examined the mediating role of workfamily conflict in the relationship between role overload and emotional exhaustion among female junior physicians. Besides its contribution to the establishment of the mediation model which incorporates the interface of work and family roles as a mediator variable, the significance of the research findings lies in its contribution towards improving junior physicians well-being,

Relationship between role overload and emotional exhaustion: Research findings support the notion that workload is a significant stressor associated with a variety of deleterious psychological reactions, including emotional exhaustion, in different samples of workers (Chopra et al., 2004; Piesah et al., 2009; Maslach et al., 2001). Excessive workload occurs when an employee perceives that he or she has too many tasks to do in a period of time. Results of a study by Greenglass et al. (2003) and Innstrand et al. (2008) has shown that nurses' perceptions of increased workload following hospital restructuring directly increased their level of distress which comprised of cynicism, anger and emotional exhaustion with the last as an important component. A significant relationship between role overload and emotional exhaustion in a sample of professional engineers in the construction industry was also reported by Yip et al. (2008) and (Maslach et al., 2001) and among public accountants by Sweeney and Summers (2002) and (Bakker et al., 2005). A longitudinal study on emotional exhaustion by Houkes et al. (2003) and (Jones et al., 2010) has shown that emotional exhaustion is influenced by variables related to working conditions including workload. Peiro et al. (2001) and Fu and Shaffer (2001) found that health care professionals' role overload predicted changes over time in emotional exhaustion. Thus empirical evidences seem to support the relationship between role overload and emotional exhaustion and the following hypothesis was tested.

H1: There is a significant relationship between role overload and emotional exhaustion.

Relationship between role overload and work-family conflict: There are many studies examining the characteristics of work domain as antecedents of workfamily conflict. One of the characteristics is role overload. When the total demand on time and energy are too great for an individual to perform the roles adequately or comfortably, role overload occurs (Yip et al., 2008). Individuals who occupy work roles and perceive that their workload is more than they can handle, would experience greater work-family conflict (Greenhaus and Beutell, 1985; Lingard and Francis, 2006). Based on previous research findings, it is expected that junior physicians who have to perform more demanding work would experience a greater intensity of work-family conflict and the following hypothesis was tested.

$\mathrm{H} 2$ : There is a significant relationship between role overload and work-family conflict.

Relationship between work-family conflict and emotional exhaustion: One of the outcomes of workfamily conflict is emotional exhaustion. A study by Burke and Greenglass (2001) and Sweeney and Summers (2002) on nursing staff during hospital restructuring has shown that increased job burnout is an important consequence of work-family conflict. A longitudinal study of individuals from eight occupational groups including physicians revealed that increased levels of work-family conflict results in higher levels of burnout including emotional exhaustion (Baron and Kenny, 1986a; Bergman et al., 2008). Similar results have been reported by Peiro et al. (2001) (Fu and Shaffer, 2001) among health care professionals, Lingard and Francis (2006) and Ray and Miller (1994) among construction professionals and managers, as well as Montgomery et al. (2003) and Houkes et al. (2003) in their study on newspaper managers. Based on previous research findings, it is expected that a higher intensity of work-family conflict experienced by junior physicians lead to greater emotional exhaustion and the following hypothesis was tested.

H3: There is a significant relationship between workfamily conflict and emotional exhaustion 


\section{J. Social Sci., 6 (2): 265-271, 2010}

Work-family conflict as a mediator in the role overload-emotional exhaustion relationship: The mediation model is developed based on the Conservation Of Resources (COR) theory (Barnett and Hyde, 2001), as well as the work of previous researchers. The COR theory proposes that individuals seek to acquire and maintain resources to reduce stress. Stress is a reaction to an environment in which there is the threat of a loss of resources, an actual loss in resources, or lack of an expected gain in resources. Resources include objects, conditions, personal characteristics and energies. Reduced workload is a condition that employees may need to cope with conflict that stems from work-family interface. The absence of this condition may cause the experience of stress such as work-family conflict. According to the COR theory this conflict in turn could lead to stress because resources are lost in the process of juggling both work and family roles. The potential or actual loss of these resources results in emotional exhaustion. Once employees are confronted with high levels of conflict in work-family interface, they are likely to be emotionally exhausted. The COR theory has been used by Grandey and Cropanzano (1999) and Burke and Greenglass (2001) in their research on the consequence of stressors on work-family conflict.

Literature have also pointed out that there is a relationship between role overload and work-family conflict on the one hand and between work-family conflict and emotional exhaustion, on the other. Based on the COR theory and previous research findings, one could argue that changes in the levels of role overload could lead to changes in the levels of work-family conflict and in turn in the levels of emotional exhaustion and thus the following hypothesis was tested.

H4: Work-family conflict mediates the relationship between role overload and emotional exhaustion.

\section{MATERIALS AND METHODS}

Sample and procedure: The sample of this present study consisted of female physicians aged 40 and below working in fourteen public hospitals (eleven state hospitals and three teaching hospitals) in Peninsular Malaysia. The age limit was established since physicians tend to have more work load at this stage of their career span. Studies have shown that younger physicians experience high levels of burnout including emotional exhaustion (Peiro et al., 2001; Maslach, 1993; Lingard and Francis, 2006). Data were collected from a sample of 380 female physicians using selfadministered questionnaires through the drop and collect method. Two hundred and twenty $(60 \%)$ female physicians returned the questionnaires. The questionnaire was first constructed in English language and then translated into Malay and was validated by back-translation to ensure that both versions were equivalent. The questionnaire was administered in both the Malay and English language and the physicians were given the alternative to choose either of the two languages.

Measurement: Work-family conflict. The level of work-family conflict was measured using an interrole scale originally developed by Pleck et al. (1980) and Montgomery et al. (2003). This scale consists of eight items based on the three most prevalent aspects of work interference with family, namely excessive work time, schedule conflict and fatigue or irritability. Responses were coded on a 5-point scaled response options ranging from strongly disagree (1) to strongly agree (5). Examples of items are: "My schedule often conflicts with my family life"; "My work takes up time that I would like to spend with my family". The reliability coefficient (alpha) of the work-family conflict scale was 0.83 .

Role overload: Role overload was measured using 8 items. Three of the items were adopted from the instruments developed by Bohen and Viveros-Long (1981) and Hobfoll (1989), three by Cook and Rousseau (1984) and Grandey and Cropanzano (1999) and two by Kahn et al. (1964) and Pleck et al. (1980). The respondents were requested to respond using five-point scaled response options ranging from strongly disagree (1) to strongly agree (5). Examples of items are: "I feel that I have too much work to accomplish compared with my ability to do them comfortably"; "I feel physically tired when I reach home from work". The reliability coefficient (alpha) of this role overload scale was 0.89 .

Emotional exhaustion: The level of emotional exhaustion was assessed using a five-item scale from Ray and Miller (1994) and Bohen and Viveros-Long (1981). The scale was an adaptation of the Maslach Burnout Inventory (MBI). The 7 point scale ranging from never (1) to every day (7) was changed to a 5 point scale ranging from never (1) to every day (5). The change was made for the purpose of consistency with the overall format of the questionnaire and to obtain consistent scores from the respondents. Examples of items are: "I feel emotionally drained from my work"; "I feel used up at the end of the workday". The reliability coefficient (alpha) of the emotional exhaustion scale was 0.84 . 
Statistical analysis: Descriptive statistics were calculated to describe the main characteristics of the subject. Correlation coefficients were computed to examine the relationships between role overload, work-family conflict and emotional exhaustion. A series of regression analyses was employed to test the hypotheses of the study. Baron and Kenny (1986b) and recommended the use of a series of regression models to test the meditational hypothesis. Testing for mediation requires the estimation of the four following regression equations: First, regressing the dependent variable on the independent variable; second, regressing the mediator on the independent variable; third, regressing the dependent variable on the mediator; and fourth, regressing the dependent variable on both the independent variable and on the mediator.

The following are the four conditions for establishing mediation; (1) The independent variable significantly affect the dependent variable; (2) The independent variable significantly affect the mediator; (3) The mediator significantly affect the dependent variable; (4) The effect of the independent variable on the dependent variable shrinks upon the addition of the mediator to the model. If the independent variable does not affect the dependent variable upon regressing the dependent variable on both the independent variable and on the mediator, then full mediation is established. If otherwise, the test supports partial mediation.

Model: This study is based on the following model which examines the mediating role of work-family conflict in the relationship between role overload and emotional exhaustion:

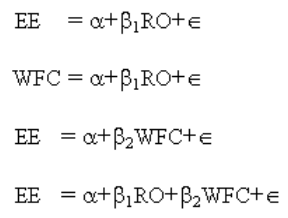

Where:

$\mathrm{EE}=$ Emotional Exhaustion

RO = Role Overload

$\mathrm{WFC}=$ Work-Family Conflict

\section{RESULTS}

Table 1 presents the characteristics of the respondents. The respondents' age ranged from 2540 years $(\mathrm{M}=32.18, \mathrm{SD}=3.56)$ with $79.5 \%$ aged from 25-35. They had an average of 4.73 years of experience $(\mathrm{SD}=3.26)$ and $69.4 \%$ had 5 years or less of experience in the present job. Majority (74.4\%) of the physicians in this study had 1 to 2 children $(\mathrm{M}=2.08$, $\mathrm{SD}=1.12$ ).

The mean score for work-family conflict on a fivepoint scale was 3.34 ( $\mathrm{SD}=0.81$ ), role overload was $3.18(\mathrm{SD}=0.73)$ and emotional exhaustion was 3.11 $(\mathrm{SD}=0.64)$ which were all above the scale mid-point (3.0) (Table 2). Correlation analysis results revealed that there were significant correlations between role overload and emotional exhaustion $(\mathrm{r}=0.56, \mathrm{p}<0.001)$ and work-family conflict $(\mathrm{r}=0.55, \mathrm{p}<0.001)$ and between work-family conflict and emotional exhaustion $(\mathrm{r}=0.55, \mathrm{p}<0.001)$. (Table 2$)$ The results support $\mathrm{H} 1$, $\mathrm{H} 2$ and $\mathrm{H} 3$.

Table 1: Characteristics of respondents

\begin{tabular}{lrrrr}
\hline Characteristic & Frequency & $(\%)$ & Mean & SD \\
\hline Age (years) & & & 32.18 & 3.56 \\
$25-30$ & 87 & 39.8 & & \\
$31-35$ & 87 & 39.7 & & \\
$36-40$ & 45 & 20.5 & & \\
Working experience & & & 4.73 & 3.26 \\
(years) & & & & \\
$\leq 5$ & 152 & 69.4 & & \\
$6-10$ & 53 & 24.2 & & \\
$11-15$ & 13 & 5.9 & & \\
$>15$ & 1 & 0.5 & & \\
Number of children & & & 2.08 & 1.12 \\
$1-2$ & 172 & 74.4 & & \\
$3-4$ & 51 & 22.1 & & \\
$>4$ & 8 & 3.5 & & \\
\hline
\end{tabular}

Table 2: Means, standard deviations and intercorrelations of the variables

\begin{tabular}{llllll} 
Table 2: Means, standard deviations and intercorrelations of the variables & & \\
\hline Variable & 1 & 2 & 3 & M & \\
\hline Work-family conflict & - & $0.55^{* * *}$ & $0.55^{* * *}$ & 3.34 & SD \\
Role overload & - & $0.56^{* * *}$ & 3.18 & 0.81 \\
Emotional exhaustion & & - & 3.11 & 0.73 \\
\hline Note: $* * *: \mathrm{p}<0.001$ & & & & 0.64 \\
\hline
\end{tabular}

Table 3: Results of multiple regression analyses

\begin{tabular}{llll}
\hline Criterion variable & Predictor variable & Beta & Adj R \\
\hline Emotional exhaustion & Role overload & $0.56^{* * *}$ & 0.31 \\
Work-family conflict & Role overload & $0.55^{* * *}$ & $97.54^{* * *}$ \\
Emotional exhaustion & Work-family conflict & $0.55^{* * *}$ & $91.36^{* * *}$ \\
Emotional exhaustion & Work-family conflict & $0.35^{* * *}$ & 0.30 \\
& Role overload & $0.37^{* * *}$ & 0.39 \\
\hline
\end{tabular}




\section{J. Social Sci., 6 (2): 265-271, 2010}

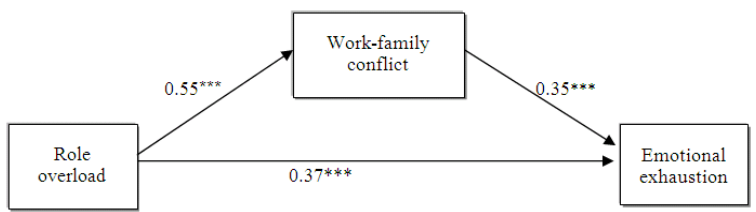

Fig. 1: Results of multiple regression analyses with WFC as a mediator of the relationships between role overload and emotional exhaustion. Note: $* * *: \mathrm{p}<0.001$ for $\beta$ values

A series of regression analyses were used to examine the role of work-family conflict as a mediator of the relationship between role overload and emotional exhaustion. Applying the four conditions for establishing mediation on the four equations of the model, it was found that these conditions hold, indicating that work-family conflict mediates the relationship between role overload and emotional exhaustion, thus supporting H4. Since the independent variable does affect the dependent variable upon regressing the dependent variable on both the independent variable and on the mediator, then partial mediation is established (Fig. 1).

The results indicate that role overload could increase the work-family conflict experienced by physicians which in turn could increase the emotional exhaustion experienced by them. Role overload explained $31 \%$ of the variance in emotional exhaustion and $30 \%$ of the variance in work-family conflict. Both role overload and work-family conflict explained $39 \%$ of the variance in emotional exhaustion, an increase in $8 \%$ of the variance (Table 3 ).

\section{DISCUSSION}

The findings of this study reveal that the junior physicians in the fourteen public hospitals experience a considerable level of emotional exhaustion. Such findings are in line with those of other studies which have shown that younger physicians experience high levels of burnout including emotional exhaustion (Peiro et al., 2001; Maslach, 1993; Lingard and Francis, 2006). This is expected considering the level of role overload experienced by them which is above the scale mid-point. Junior physicians tend to have more work load at this stage of their career span. The excessive work of junior physicians have to perform has been emphasized by Shaufelli et al. (2009) (Lingard and Francis, 2006). In this present study, the heavy workload and on-calls (2-3 times per week for physicians in government hospitals) indicate that the physicians feel that they had more work than they could handle comfortably. According to Houkes et al. (2003);
Jones et al. (2010); Peiro et al. (2001) and Fu and Shaffer (2001) employees with excessive workload would experience negative emotions, fatigue and tension. Such feelings would then lead to an increase in the intensity of emotional exhaustion as indicated by the positive correlation between role overload and emotional exhaustion. Firth-Cozens (1998) had attributed the role overload of physicians in his study to the increase in the number of outpatients to be attended each day and the increase in the number of patients in the ward. The considerably high level of role overload experienced by the physicians in this present study could be due to similar reasons.

The results that role overload is correlated with work-family conflict indicate that junior physicians who have too many tasks to do in a period of time tend to experience greater intensity of work-family conflict. The significant relationship between role overload and work-family conflict is consistent with the findings of previous research (Greenhaus and Beutell, 1985; Lingard and Francis, 2006). The significant relationship between work-family conflict and emotional exhaustion indicate that physicians who experience greater conflict resulting from performing both work and family roles tend to experience greater emotional exhaustion. Similar results were obtained by (Ray and Miller, 1994; Baron and Kenny, 1986a; Bergman et al., 2008; Fu and Shaffer, 2001; Houkes et al., 2003).

Theoretically, the findings have shown that the COR theory could help explain the model whereby loss of resources or energy and time due to role overload, such that an individual could not perform the role adequately or comfortably, results in stress or emotional exhaustion. The loss of these resources also results in work-family conflict. Work-family conflict could in turn lead to emotional exhaustion because resources are lost in the process of juggling both work and family roles. The results support the notion that workload is a significant stressor associated with a variety of deleterious psychological reactions, including workfamily conflict and emotional exhaustion.

Several limitations of this study should be noted. First, a significant limitation of the present investigation is the small sample size that is utilized. The results reported here may only be generalized to female junior physicians meeting the selection criteria (married and aged 40 years and below) in the fourteen public hospitals in Malaysia, but any assumption of external validity beyond that is cautioned. Second, with the moderate level of response rate of $60 \%$, there might be non-response bias; the physicians who do not respond may differ systematically from the study's respondents. It is possible that the physicians who do not respond may be experiencing higher levels of role overload at the workplace and this might in turn affect the results 
and conclusions of the study. Third, the inferences drawn from this study are limited by self-reported and cross-sectional characteristics of the data.

This research enables some recommendations to be made for the adoption of future policies by the Ministry of Health to help reduce the role overload experienced by junior physicians. This will enable physicians to achieve a greater work-family balance and feel less emotionally drained. One of the recommendations is to review the ratio between physicians and patients that has a great implication on role overload. Another recommendation is the re-assessment of the working hours of physicians and the weekly frequency of oncalls and the total number of hours that physicians have to spend on on-call duties. Limiting on-call frequency and hours may be more likely to reduce the level of work-family conflict experienced that could in turn reduce the level of emotional exhaustion. The management should avoid seeing the problem of role overload in isolation from that of work-family conflict since problems related to these stressors could affect the psychological wellbeing of junior physicians.

\section{CONCLUSION}

Work-family conflict partially mediated the effects of role overload on emotional exhaustion. Junior physicians who experience role overload seem to be more emotionally drained and seem to experience greater conflict between work and family roles.

\section{REFERENCES}

Alacacioglu, A., T. Yavuzsen, M. Dirioz, O. Ilhan and U. Yilmaz, 2009. Burnout in nurses and physicians working at an oncology department. PsychoOncology, 18: 543-548. DOI: 10.1002/pon.1432.

Bakker, A.B., E. Demerouti and M.C. Euwema, 2005. Job resources buffer the impact of job demands on burnout. J. Occup. Health Psychol., 10: 170-180. DOI: 10.1037/1076-8998.10.2.170

Barnett, R.C. and J.S. Hyde, 2001. Women, men, work and family: An expansionist theory. Am. Psychol., 56: 781-796.

http://www.biomedexperts.com/Abstract.bme/1167 5985/Women_men_work_and_family_An_expansi onist_theory

Baron, R.M. and D.A. Kenny, 1986a. The moderatormediator variable distinction in social psychology research: Conceptual, strategic and statistical considerations. Work family balance, stress and salivary cortisol in men and women academic physicians. Int. J. Behav. Med., 15: 54-61. DOI: 10.1080/10705500701783942
Baron, R.M. and D.A. Kenny, 1986b. The moderatormediator variable distinction in social psychology research: Conceptual, strategic and statistical considerations. J. Person. Soc. Psychol., 5: 1173-1182. DOI: 10.1037/0022-3514.51.6.1173

Bergman, B., F. Ahmad and D.E. Stewart, 2008. Work family balance, stress and salivary cortisol in men and women academic physicians. Int. J. Behav. Med., 15: 54-61. DOI: 10.1080/10705500701783942

Bohen, H.H. and A. Viveros-Long, 1981. Balancing Jobs and Family Life: Do Flexible Work Schedules Help? Temple University Press, Philadelphia, pp: 236.

Burke, R.J. and E.R. Greenglass, 2001. Hospital restructuring, work-family conflict and psychological burnout among nursing staff. Psychol. Health, 16: 583-595. DOI: 10.1080/08870440108405528

Chopra, S.S, W.M. Sotile and M.O. Sotile, 2004. Physician burnout. J. Am. Med. Assoc., 291: 633. http://jama.ama-assn.org/cgi/content/full/291/5/633

Cook, R.A. and D.M. Rousseau, 1984. Stress and strain from family roles and work role expectation. J. Applied Psychol., 69: 250-260. DOI: 10.1037/0021-9010.69.2.252

Firth-Cozens, J., 1998. Individual and organizational predictors of depression in general practitioners. Br. J. General Pract., 48: 1647-1651. http://www.ncbi.nlm.nih.gov/pmc/articles/PMC131 3238/pdf/10071396.pdf

Fu, C.K. and M.A. Shaffer, 2001. The tug of work and family: Direct and indirect domain-specific determinants of work-family conflict. Person. Rev., 30: 502-522. DOI: 10.1108/EUM0000000005936.

Grandey, A.A. and R. Cropanzano, 1999. The conservation of resources model applied to workfamily conflict and strain. J. Vocat. Behav., 54: 350-370. DOI: 10.1006/jvbe.1998.1666

Greenglass, E.R., R.J. Burke and K.A. Moore, 2003. Reactions to increased workload: Effects on professional efficacy on nurses. Applied Psychol. Int. Rev., 52: 580-597. DOI: 10.1111/14640597.00152

Greenhaus, J.H. and N. Beutell, 1985. Sources of conflict between work and family roles. Acad. Manage. $\quad$ Rev., $\quad$ 10: 76-88. http://search.ebscohost.com/login.aspx?direct=true $\& \mathrm{db}=\mathrm{bth} \& \mathrm{AN}=4277352 \&$ site=ehost-live

Hobfoll, S.E., 1989. Conservation of resources. A new attempt at conceptualizing stress. Am. Psychol., 44: 513-524. DOI: 10.1037/0003-066X.44.3.513 
Houkes, I., P.P.M. Janssen, J. De Jonge and A.B. Bakker, 2003. Specific determinants of intrinsic work motivation, emotional exhaustion and turnover intention: A multisample longitudinal study. J. Occup. Org. Psychol., 76: 427-450. http://web.ebscohost.com/ehost/pdfviewer/pdfview er?vid=16\&hid=105\&sid=010aa287-6d19-4460aa2c-304a0d9d7401\%40sessionmgr104

Innstrand, S.T., E.M. Langballe, G.A. Espnes, E. Falkum and O. Aasland, 2008. Positive and negative workfamily interaction and burnout: A longitudinal study of reciprocal relations. Stress and Stress, 22: 1-15. DOI: 10.1080/02678370801975842

Jones, A., C.S. Norman and B. Wier, 2010. Healthy lifestyle as a coping mechanism for role stress in public accounting. Behav. Res. Account., 22: 21-41. DOI: 10.2308/bria.2010.22.1.21

Kahn, R.L., D.M. Wolfe, R. Quinn, J.D. Snoek and R.A. Rosenthal, 1964. Stress Studies in Role Conflict and Ambiguity. Wiley, New York, ISBN: 10: 047145480X, pp: 470.

Lingard, H. and V. Francis, 2006. Does a supportive work environment moderate the relationship between work-family conflict and burnout among construction professionals? Construct. Manage. Econ., 24: 185-196. DOI: 10.1080/14697010500226913

Maslach, C., 1993. Burnout: A Multidimensional Perspective. In: Recent Developments in Theory and Research, Schaufeli, W.B., C. Maslach and T. Marek (Eds.). Professional Burnout, Taylor and Francis, Washington DC., USA., ISBN: 1560322624, pp: 19-32.

Maslach, C., W.B. Schaufeli and M.P. Leiter, 2001. Job burnout. Ann. Rev. Psychol., 52: 397-422. DOI: 0066-4308/01/0201-0397

Montgomery, A., M.C.W. Peeters, W.B. Schaufeli and M. Den Ouden, 2003. Work-home interference among newspaper managers: Its relationship with burnout and engagement. Anxiety Stress Cop., 16: 195-211. DOI: 10.1080/1061580021000030535
Peiro, J.M., Gonzalez-Roma, V., Tordera, N. and Manas, M.A., 2001. Does role stress predict burnout over time among health care professionals? Physiol. Health, 16: 511-526. DOI: 10.1080/08870440108405524

Piesah, C., E. Latif, K. Wilhelm and B. Williams, 2009. Secrets to psychological success: Why older doctors might have lower psychological distress and burnout then younger doctors. Aging Mental Health, 13: 300-307. DOI: $10.1080 / 13607860802459831$

Pleck, J., G. Staines and L. Lang, 1980. Conflicts between work and family life. Monthly Labor Rev., 103: 29-32. http://search.ebscohost.com/login.aspx?direct=true $\& \mathrm{db}=\mathrm{bth} \& \mathrm{AN}=6002127 \&$ site $=$ ehose-live

Ray, E.B. and K.I. Miller, 1994. Social support, home/work stress and burnout: Who can help? J. Applied Behav. Sci., 30: 357-3373. DOI: 10.1177/0021886394303007

Shaufelli, W.B., A.B. Bakker, F.M.M.A. van der Heijden and J.T. Prins, 2009. Workaholism, burnout and well-being among junior doctors: The mediating role of role conflict. Work Stress, 23: 155-172. DOI: $10.1080 / 02678370902834021$

Sweeney, J.T. and S.L. Summers, 2002. The effect of the busy season workload on public accountants' job burnout. Behav. Res. Account., 14: 223-245. http://www.accessmylibrary.com/article-1G184211301/effect-busy-season-workload.html

Yip, B., S. Rowlinson and O.L. Siu, 2008. Coping strategies as moderators in the relationship between role overload and burnout. Construct. Manage. Econ., 26: 869-880. DOI: $10.1080 / 01446190802213529$ 